Article

\title{
Effect of Nardostachys jatamansi DC. on Apoptosis, Inflammation and Oxidative Stress Induced by Doxorubicin in Wistar Rats
}

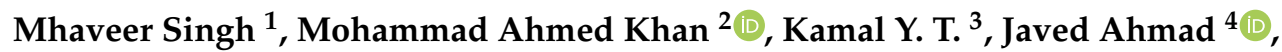 \\ Usama A. Fahmy 5,6 (D), Sabna Kotta ${ }^{5}$, Nabil A. Alhakamy ${ }^{5,6}$ iD and Sayeed Ahmad 7 ,* \\ 1 School of Medical and Allied Sciences, G D Goenka University, Haryana 122103, India; \\ mhaveer.singh@gdgoenka.ac.in \\ 2 Department of Pharmacology, School of Pharmaceutical Education \& Research, Hamdard University, \\ Hamdard Nagar, New Delhi 110062, India; drm.ahmedkhan@jamiahamdard.ac.in \\ 3 Department of Pharmacognosy, College of Pharmacy, King Khalid University, Abha 611441, Saudi Arabia; \\ kamal.yt@gmail.com \\ 4 Department of Pharmaceutics, College of Pharmacy, Najran University, Najran 11001, Saudi Arabia; \\ jaahmed@nu.edu.sa \\ 5 Department of Pharmaceutics, Faculty of Pharmacy, King Abdulaziz University, Jeddah 21589, Saudi Arabia; \\ uahmedkauedu.sa@kau.edu.sa (U.A.F.); skotta@kau.edu.sa (S.K.); nalhakamy@kau.edu.sa (N.A.A.) \\ 6 Center of Excellence for Drug Research \& Pharmaceutical Industries, King Abdulaziz University, \\ Jeddah 21589, Saudi Arabia \\ 7 Bioactive Natural Product Laboratory, School of Pharmaceutical Education \& Research, Hamdard University, \\ Hamdard Nagar, New Delhi 110062, India \\ * Correspondence: sahmad_jh@jamiahamdard.ac.in
}

Received: 14 October 2020; Accepted: 6 November 2020; Published: 15 November 2020

\begin{abstract}
The study aimed to investigate the protective action of jatamansi (Nardostachys jatamansi DC.) against doxorubicin cardiotoxicity. Methanolic extract of jatamansi (MEJ) was prepared and standardized using HPTLC fingerprinting, GC-MS chemoprofiling, total phenolic content, and antioxidant activity in vitro. Further in vivo activity was evaluated using rodent model. Animals were divided into five groups $(n=6)$ namely control (CNT) (Normal saline), toxicant (TOX, without any treatment), MEJ at low dose (JAT1), MEJ at high dose (JAT2), and standard desferrioxamine (STD). All groups except control received doxorubicin $2.5 \mathrm{mg}$ per Kg intra-peritoneally for 3 weeks in twice a week regimen. After 3 weeks, the blood samples and cardiac tissues were collected from all groups for biochemical and histopathological evaluation. Treatment with MEJ at both dose levels exhibited significant reduction ( $p<0.001$ vs. toxicant) of serum CK-MB (heart creatine kinase), LDH (Lactate dehydrogenase) \& HMG-CoA (3-hydroxy-3-methylglutaryl-coenzyme A) levels, and tissue MDA (melondialdehyde) level; insignificant difference was observed $(p>0.05)$ in TNF-alpha (tumour necrosis factor), IL-6 (interleukine-6) levels and caspase activity as compared to TOX. Histopathological evaluation of cardiac tissues of different treatment groups further reinforced the findings of biochemical estimation. This study concludes that jatamansi can protect cardiac tissues from oxidative stress-induced cell injury and lipid peroxidation as well as against inflammatory and apoptotic effects on cardiac tissues.
\end{abstract}

Keywords: biochemical estimation; cardioprotection; cardiotoxicity; doxorubicin; lipid peroxidation; Nardostachys jatamansi DC. 


\section{Introduction}

Doxorubicin (DOX) is a clinically useful anticancer drug being used in the management of different types of cancers including lymphomas and carcinomas [1,2]. However, the major problem associated with its clinical use is the development of dose-dependent cardiotoxicity [2]. DOX cardiotoxicity can occur acutely (within 3 days) upon administration whereas chronic toxicity is seen within 30 days of the last dose. The exact cause of DOX-induced preferential cardiotoxicity is poorly understood despite exhaustive research and investigation [3]. Different lines of evidence, however, obtained through preclinical studies have proposed a number of mechanisms for cardiotoxicity of DOX including the induction of oxidative stress [4], cardiomyocyte apoptosis at acute as well as chronic levels [5-8], iron mediated stress [9], adrenergic dysfunction, and abnormal handling of calcium [10-12]. However, DOX-induced cardiotoxicity has been shown to be induced through pathways independent of cytotoxic mechanisms. Therefore, a strategy can be developed for protecting against doxorubicin-induced cardiotoxicity without affecting the therapeutic value of the drug [13].

Nardostachys jatamansi DC., commonly known as jatamansi, is an important medicinal herb of Indian origin, belonging to the family Caprifoliaceae. Jatamansi belongs to valerian subfamily, which includes herbaceous flowering plants, which sometimes have a characteristic odor (Figure 1). It is an important part of various traditional systems of medicines to treat different disorders [14-17]. It has been used in traditional medicines for the treatment of cardiac and many other diseases. It is reported to possess anti-hypertensive, antispasmodic, sedative, and anxiolytic activity. Its use for the treatment of hyperglycemic and inflammatory conditions has also been reported in traditional literature [18]. Various sesquiterpenes such as lignans and neolignans are present in root extracts of plants [19] and have been suggested to protect cells and tissues through their antioxidant properties [20]. Recently, in a rodent model of inflammation, jatamansi has been shown to inhibit the production of interleukin-1 (IL-1), interleukin-6 (IL-6), tumor necrosis factor (TNF-alpha), and interferon (IFN- $\alpha / \beta$ ) by inhibiting MAPKs (Mitogen-activated protein kinase) activation and induction of IRF (interferon regulatory factor) [21]. However, the drug has reported protection against doxorubicin-induced lipid peroxidation [22,23]; this study is, however, designed to evaluate the possible protective role of standardized jatamansi extract on oxidative, inflammatory and apoptotic markers against DOX-induced cardiotoxicity in rats.

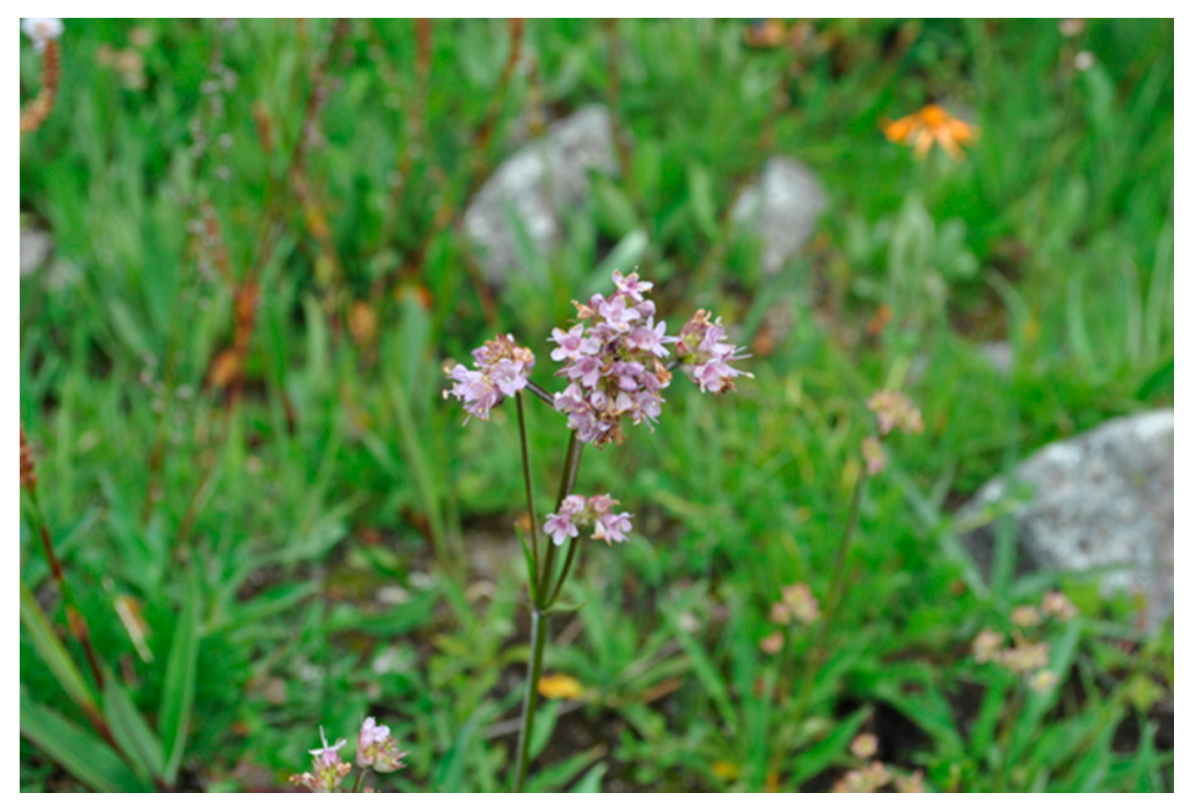

Figure 1. Nardostachys jatamansi. 


\section{Materials and Methods}

\subsection{Chemicals and Reagents}

Catechin (98\%), ascorbic acid (99\%) and 2,2-diphenyl-1-picrylhydrazyl (DPPH) were purchased from Sigma Aldrich, Missouri, USA. Sodium nitroprusside, naphthylethylene diamine dihydro chloride and sulphanilamide were provided by SRL Mumbai, India. Folin-Ciocalteau (FC) reagent, sodium carbonate $\left(\mathrm{Na}_{2} \mathrm{CO}_{3}\right), 5,5^{\prime}$-dithio-bis (2-nitrobenzoic acid) (DTNB), thiobarbituric acid (TBA), and trichloro acetic acid (TCA) were purchased from S. D. Fine, India. DOX and desferrioxamine were obtained as commercial formulations from local Pharmacy, New Delhi.

\subsection{Plant Material}

The rhizomes of jatamansi were purchased from local herbal drug market (Kharibawli, Old Delhi), which was identified and authenticated by Dr. HB Singh [Scientist F \& Head Raw Materials Herbarium \& Museum, NISCAIR (National Institute of Science Communication and Information Resources), Dr. K. S. Krishnan Marg (Near Pusa Gate), New Delhi 110 012, Voucher specimen No. NISCAIR/RHMD/Consult/-2008-09/1149/181/02/01-08].

\subsection{Extract Preparation}

The aqueous methanolic extraction of Jatamansi (MEJ) was done using dried and coarsely powdered rhizome (200 gm). The hot extraction was carried out using 70:30 v/v aqueous methanol with a reflux condenser in a water bath for $2 \mathrm{~h}$. The process was repeated three times to obtain complete extraction by adding fresh solvent and collecting the extracts. The extracts were pooled and concentrated using rota-vapour and further dried by lyophilisation (extractive value $8.76 \% w / w$ ).

\subsection{Standardization of MEJ}

\subsubsection{HPTLC Profiling}

The MEJ was reconstituted in methanol $\left(20 \mathrm{mg} \mathrm{mL}^{-1}\right)$, filtered through $0.45 \mu \mathrm{m}$ membrane filter, and HPTLC profiling was done on silica using toluene: ethyl acetate $(73: 7, v / v)$ as a solvent system. The plate was air dried and scanned at $254 \mathrm{~nm}$ wavelength.

\subsubsection{GC-MS Chemoprofiling}

The lyophlised MEJ powder was dissolved in GC-MS grade hexane $\left(1.0 \mathrm{mg} \mathrm{mL}^{-1}\right)$ and filtered. The hexane soluble constituents were GC-MS analysis on Agilent 7890A GC system coupled with 5975C inert XL E1/C1 MSD model \# G3174A, Agilent Technologies, Wilmington, DE, USA mass spectroscopic system having $30 \mathrm{~m}$ (length) $\times 250 \mu \mathrm{m} \times 0.25 \mu \mathrm{m}$ HP-5MS capillary column and autosampling system. The injector was operated in splitless mode with $1.0 \mu \mathrm{L}$ injection volume. The gas flow rate was maintained at $1.0 \mathrm{~mL} \mathrm{~min}^{-1}$, while inlet temperature was maintained at $270{ }^{\circ} \mathrm{C}$. Oven temperature was initially kept at $40^{\circ} \mathrm{C}$ for $1 \mathrm{~min}$ and then increased to $140{ }^{\circ} \mathrm{C}$ at a heating rate of $4.0^{\circ} \mathrm{C} \mathrm{min}^{-1}$ followed by $200{ }^{\circ} \mathrm{C}$ at a heating rate of $10{ }^{\circ} \mathrm{C} \mathrm{min}-1$ and lastly up to $280{ }^{\circ} \mathrm{C}$ at a heating rate of $8{ }^{\circ} \mathrm{C} \mathrm{min}^{-1}$. The total run time was $42 \mathrm{~min}$ with MS operated in SCAN mode.

\subsubsection{Determination of Total Phenolic Content and In Vitro Antixidant Potential}

The total phenolic content in MEJ was estimated using Folin-Ciocalteau reagent, and catechin was used as a standard [24]. However, free radical scavenging potential of MEJ was determined for concentrations from 5.0 to $100 \mu \mathrm{g} \mathrm{mL}^{-1}$ by DPPH method [25]. The $1 \mathrm{~mL}$ of DPPH solution $(0.004 \%$, $w / v)$ in $95 \%$ methanol was taken in test tubes, and then $1.0 \mathrm{~mL}$ of MEJ was added followed by serial dilutions (5.0-100 $\left.\mathrm{g} \mathrm{mL} \mathrm{m}^{-1}\right)$ to every test tube. Ascorbic acid was used as a reference standard and dissolved in methanol to make the stock solution with the same concentration $\left(1.0 \mathrm{mg} \mathrm{mL}^{-1}\right)$ followed by serial dilutions $\left(5.0-100 \mu \mathrm{g} \mathrm{mL}^{-1}\right)$. The absorbance was measured after $10 \mathrm{~min}$ at $515 \mathrm{~nm}$. The control 
sample was prepared containing the same volume without any extract and reference ascorbic acid, whereas methanol (95\%) was used as blank. The percentage scavenging activity of the MEJ against DPPH free radical was measured using the following Equation (1):

$$
\% \text { Inhibition }=[(\mathrm{A} 0-\mathrm{A} 1) / \mathrm{A} 0] \times 100
$$

where A0 was the absorbance of the control (blank, without extract), and A1 was the absorbance of the extract or standard.

Similarly, Nitric oxide (NO) radical scavenging activity of MEJ was determined as per the method reported by Liu et al. (2009) [26]. The method is based on the principle that sodium nitroprusside in aqueous solution at physiological $\mathrm{pH}$ spontaneously generates nitric oxide, which interacts with oxygen to produce nitrite ions; it can be determined by the use of the Griess Illosvoy reaction where scavengers of nitric oxide compete with oxygen, leading to reduced production of nitric oxide.

\subsection{In Vivo Study}

\subsubsection{Animals}

Adult male Wistar rats 10-12 weeks old weighing 200-250g were used in the study, which was approved by Institutional Animal Ethics Committee in the CPCSEA (Committee for the purpose of control and supervision of experiment on animals) proposal No. 659 obtained from Central Animal House facility of Jamia Hamdard (Hamdard University). All animals were maintained under standard laboratory conditions with standard pellet diet and free access to water. The animal rooms were maintained at $20-25^{\circ} \mathrm{C}$ with a $12 \mathrm{~h}$ light/dark cycle. All animals were subjected to humane treatment, and the study was conducted in accordance with the strict guidelines of Institutional Ethics Committee. Animals were divided into five groups $(n=6)$ namely control (CNT, group 1$)$, toxicant (TOX, group 2$)$, MEJ low dose (JAT1, group 3), MEJ high dose (JAT2, group 4), and standard (STD, group 5). The MEJ was given in two low and high doses (250 and $500 \mathrm{mg} \mathrm{mL}^{-1} \mathrm{Kg}^{-1}$ body weight day ${ }^{-1}$ ) as both the doses were found to bw effective against parkinson and stress in rats $[27,28]$.

\subsubsection{Treatment Schedule}

The CNT group was given normal saline orally at $1.0 \mathrm{~mL} / \mathrm{kg} /$ day for 3 weeks. TOX group was administered with DOX $2.5 \mathrm{mg} \mathrm{Kg}^{-1}$ body weight through intra-peritoneal route twice a week for 3 weeks along with normal saline $1.0 \mathrm{~mL} / \mathrm{kg} /$ day [29,30]. Test groups were treated with JAT1 (250 mg/kg/day) and JAT2 (500 mg/kg/day) for 3 weeks along with DOX as given for toxic control. The desferrioxamine (Desferal injection) was used as standard (STD) and administered (i.v.) 50 $\mathrm{mg} / \mathrm{kg} /$ day for 3 weeks along with DOX. The animals were anaesthetised $72 \mathrm{~h}$ after the last dose of DOX, and blood was withdrawn from the retro-orbital plexus. The blood was allowed to clot and serum was separated and stored for biochemical estimation. Further, animals were killed under high dose of anaesthesia; hearts were excised and immediately washed with ice cold saline for tissue estimations. For histopathological evaluation, the heart tissues of different groups were fixed in $10 \%$ neutral buffered formalin. The serums obtained were used for analysis of different biochemical markers, whereas heart tissue homogenate were utilised for the analysis of total protein and marker enzymes. The histopathological changes were observed using heart tissues of all groups at different magnifications after proper staining.

\subsubsection{Biochemical Estimation}

CK-MB and LDH activity was measured in serum using available kits (Reckon Diagnostics Pvt. Ltd., Vadodara, India) as per the reported method [31]. HMG-CoA was estimated using ELISA kit (Cusa Biotech Pvt. Ltd., New Delhi, India). TNF-alpha was estimated in cardiac tissue using commercial ELISA kit (e-Bioscience, Inc., San Diego, CA, USA) as per the method described by Lehmann et 
al. (2008) [32]. Quantitative measurement of IL-6 was performed in vitro in serum using Elisa kit (Ray Biotech, Inc., USA) as per the method described by Helle et al. (1991) [33]. Caspase-3 activity was measured in heart tissue using Capase-3/CPP32 colorimetric ELISA assay kit (Bio Vision, Inc., California, USA) as discussed by Jaeschke et al. (1998) [34]. Similarly, estimation of lipid peroxidation was done by the method reported by Iqbal et al. (2008) [35] and total protein estimation in both serum and heart tissue as per the method followed by Lowry et al., 1951 [36].

\subsection{Histopathology}

Heart tissue sections were stained by Haematoxylin and Eosin stain, and histopathological evaluation was carried out by a pathologist blinded to the treatment [37].

\subsection{Statistical Analysis}

Graph pad Prism3.0 (Graph pad; San Diego, CA, USA) was used for statistical analysis of results. All results were expressed as mean \pm standard deviation (SD). Data from different groups were compared with the analysis of variance (ANOVA) followed by Tukey test. Values were considered statistically significant when $p<0.05$.

\section{Results}

\subsection{Standardization of MEJ}

The HPTLC profiling of MEJ at $254 \mathrm{~nm}$ (Figure S1 in Supplementary Material) showed the presence of 10 well-separated spots corresponding to 10 different compounds at different $R_{\mathrm{f}}$. On the other hand, GC-MS chemo profiling for the hexane soluble fraction of MEJ led to separation and identification of six major constituents. Of these six constituents, jatamansone was present in the highest concentration (32.05\%) (Table 1, Figures A1 and A2 in Appendix A). The phenolic compounds reported an inhibitory effect on carcinogenesis and mutagenesis in humans [38]; the total phenolic content in the MEJ was found to be $4.12 \pm 0.09 \%, w / w$. The MEJ showed antioxidant action by inhibiting DPPH radical in a concentration-dependent manner with an $\mathrm{IC}_{50}$ values of $81.99 \mu \mathrm{g} \mathrm{mL}{ }^{-1}$. Ascorbic acid, which was used as the standard, exhibited an $\mathrm{IC}_{50}$ value of $31.36 \mu \mathrm{g} \mathrm{mL}{ }^{-1}$ (Figure 2A). Similarly, MEJ also showed concentration-dependent nitric oxide scavenging activity at the concentration of $10-200 \mu \mathrm{g} \mathrm{mL}{ }^{-1} \mathrm{with}$ an $\mathrm{IC}_{50}$ value of $60.03 \mu \mathrm{g} \mathrm{mL} \mathrm{m}^{-1}$ (Figure 2B). Ascorbic acid was also found to possess nitric oxide scavenging activity with an $\mathrm{IC}_{50}$ value of $14.44 \mu \mathrm{g} \mathrm{mL}^{-1}$. RESULTS OF GC-MS PROFILING OF MEJ.

Table 1. Results of GC-MS profiling of MeJ.

\begin{tabular}{ccccc}
\hline S. No & Name of Constituent & $\mathbf{R}_{\mathbf{t}}$ & $\begin{array}{c}\text { Area } \\
\text { Percentage }\end{array}$ & $\begin{array}{c}\text { Matching } \\
\text { Percentage }\end{array}$ \\
\hline 1 & Seychellene & 16.957 & 5.67 & 96 \\
2 & Acenaphthylene & 21.019 & 22.36 & 55 \\
3 & Patchouli alcohol & 23.222 & 21.73 & 98 \\
4 & Jatamansone & $\mathbf{2 3 . 6 0 6}$ & $\mathbf{3 2 . 0 5}$ & $\mathbf{9 9}$ \\
5 & 1-methyl-4-chloro-3,5-dimethoxy-1H-pyrazole & 25.866 & 8.30 & 60 \\
6 & Illudol \$\$ 3,6,6,7b-tetramethyl & 26.015 & 9.89 & 44 \\
\hline
\end{tabular}




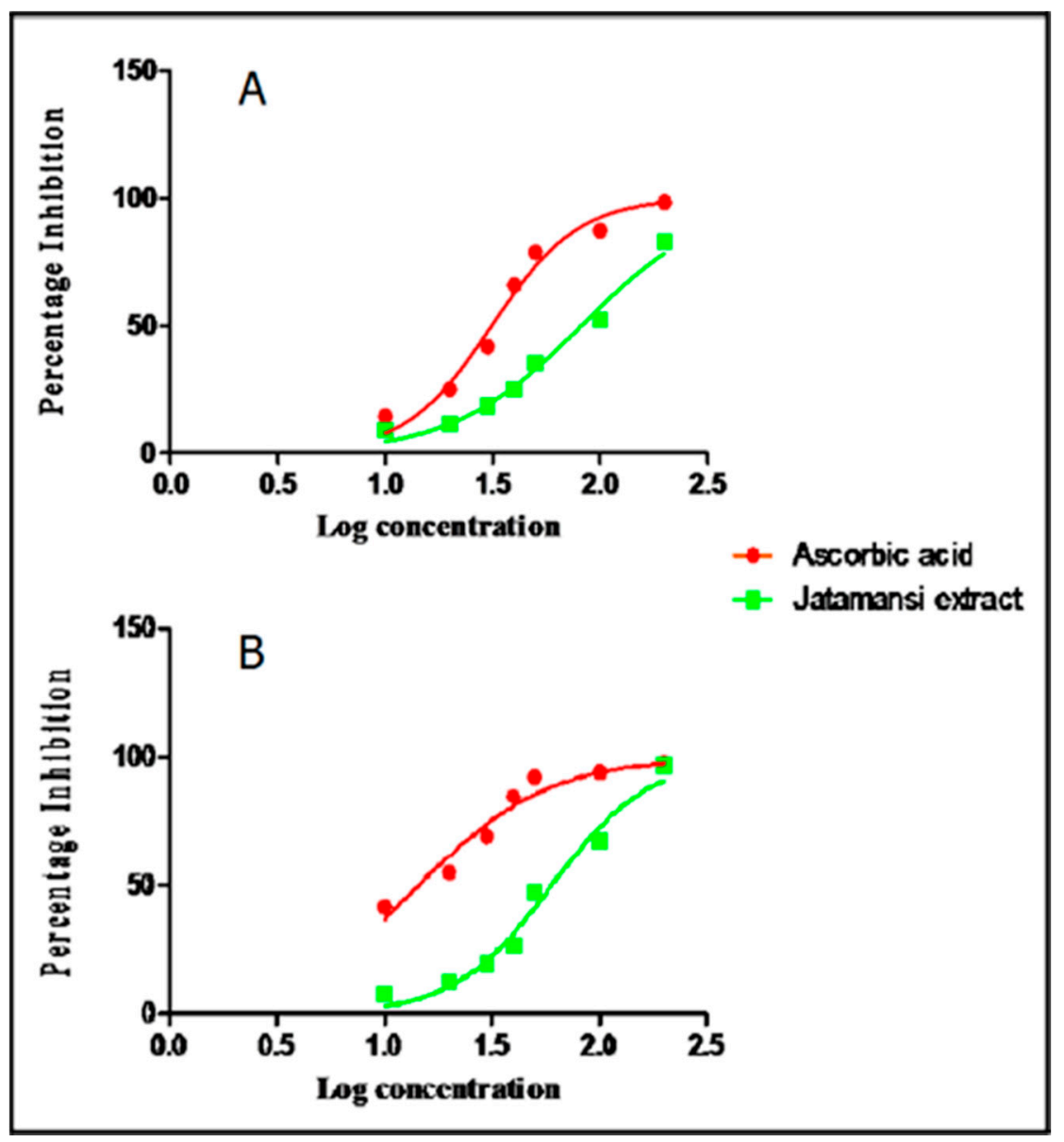

Figure 2. Antioxidant potential of MEJ compared with ascorbic acid by using DPPH (A) and Nitric oxide (B) scavenging method.

\subsection{In Vivo Study}

Biochemical Estimation

Results of CK-MB estimation in the serum of different experimental groups showed that CK-MB level in TOX group was significantly elevated ( $p<0.001 \mathrm{vs.} \mathrm{CNT).} \mathrm{Treatment} \mathrm{with} \mathrm{MEJ} \mathrm{and} \mathrm{STD} \mathrm{caused}$ significant reduction in the elevated CK-MB level ( $p<0.001$ vs. TOX) (Figure 3A). Similarly, TOX group treatment caused an elevation in the mean serum LDH level $(p<0.001 v s$. CNT), while treatment with either MEJ or STD showed a significant reduction in the elevated LDH level ( $p<0.001 \mathrm{vs.} \mathrm{TOX)}$ (Figure 3B). Mean tissue MDA levels estimated as a measure of lipid peroxidation ( $\mathrm{nmol} \mathrm{mg}^{-1}$ of protein) were found to be significantly elevated in the TOX group $(p<0.001 \mathrm{vs.} \mathrm{CNT).} \mathrm{However,}$ a significant reduction of MDA levels was observed upon treatment with MEJ and STD ( $p<0.001 \mathrm{vs.}$ TOX) (Figure 3C). TOX group showed significant elevation in HMG-CoA levels ( $p<0.001 \mathrm{vs.} \mathrm{CNT).}$ However, MEJ- and STD-treated groups caused a significant reduction in elevated HMG-CoA level $(p<0.001 \mathrm{vs}$. TOX) (Figure 3D). In agreement with the previous observations, TOX treatment also caused significant elevation in cardiac tissue caspase-3 activity, serum IL-6 and TNF-alpha levels $\left(p<0.001\right.$ vs. CNT). Whereas, MEJ treated groups at 250 and $500 \mathrm{mg} \mathrm{kg}^{-1}$ showed significant reduction in $(p<0.05)$ in the levels of these cytokines in comparison to the TOX group. STD group also showed a significant reduction $(p<0.001 \mathrm{vs}$. TOX) of TNF-alpha, IL-6 as well as caspase-3 levels compared to TOX (Figure 3E-G). 


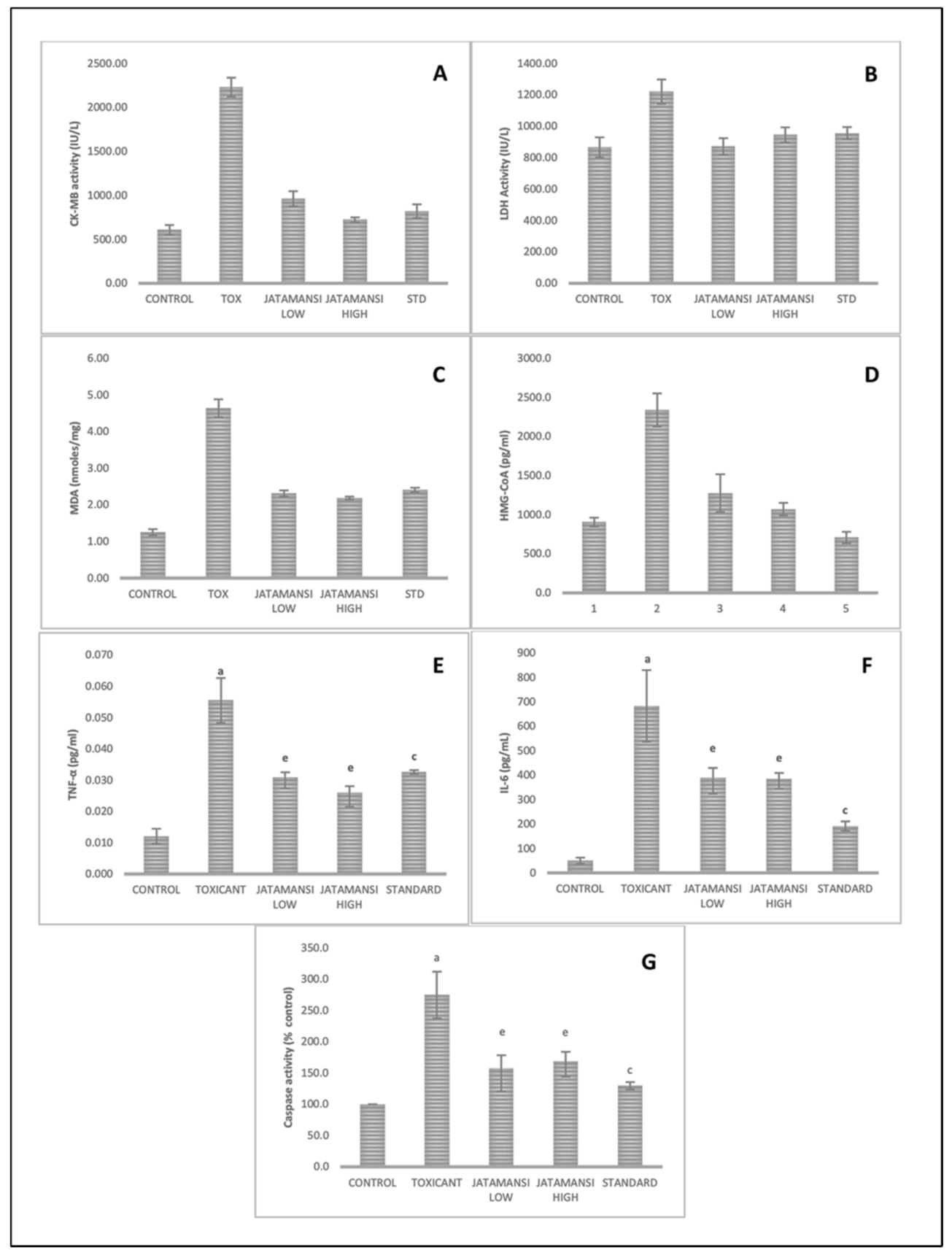

Figure 3. Results of different biochemical parameters for CNT group, TOX group, STD, MEJ $250 \mathrm{mg} / \mathrm{kg}$ (JAT1), and $500 \mathrm{mg} / \mathrm{kg}$ treated group (JAT2). (A) serum CK-MB level where TOX group showed a significant increase ( $p<0.01$ vs. Control) in CK-MB activity, indicating myocardial damage. Treatment with Jatamansi exhibited a significant reduction in CK-MB activity. (B) serum LDH activity was significantly increased with DOX treatment. This effect was reversed upon treatment with Jatamansi. (C)Tissue MDA (TBARS) level was elevated significantly compared to control group, which indicates severe lipid peroxidation and oxidative stress. Jatamansi at both dose levels prevented elevation of MDA levels significantly; (D) serum HMG-CoA level, which was similar to other mentioned parameters, was significantly low in Jatamansi-treated animals; Serum inflammatory marker TNF- $\alpha$ (E) and IL-6 (F) also showed elevated levels upon DOX treatment. The anti-inflammatory effect of Jatamansi was evident from lowering of TNF- $\alpha$ and IL-6 levels as compared to DOX. (G) \% caspase activity measured as marker of apoptosis showed a significant increase in cardiac tissue of DOX-treated animals. 


\subsection{Histopathology}

Samples from cardiac tissues from animals belonging to CNT, DOX, MEJ (JAT1 and JAT2), and STD treatment groups were examined with special reference to histological evidence in reference to DOX-induced cardiac damage. Normal myocardial tissue architecture was observed in the CNT group. On the other hand, myocardial tissue from TOX group exhibited disarrayed fibres and vacuolar myopathy with evidence of necrosis. The large disarray and vacuolar myopathy were not observed in the myocardial tissue samples from MEJ-treated (250 and $500 \mathrm{mg} / \mathrm{kg} /$ day) as well as STD treatment groups (Figure 4).

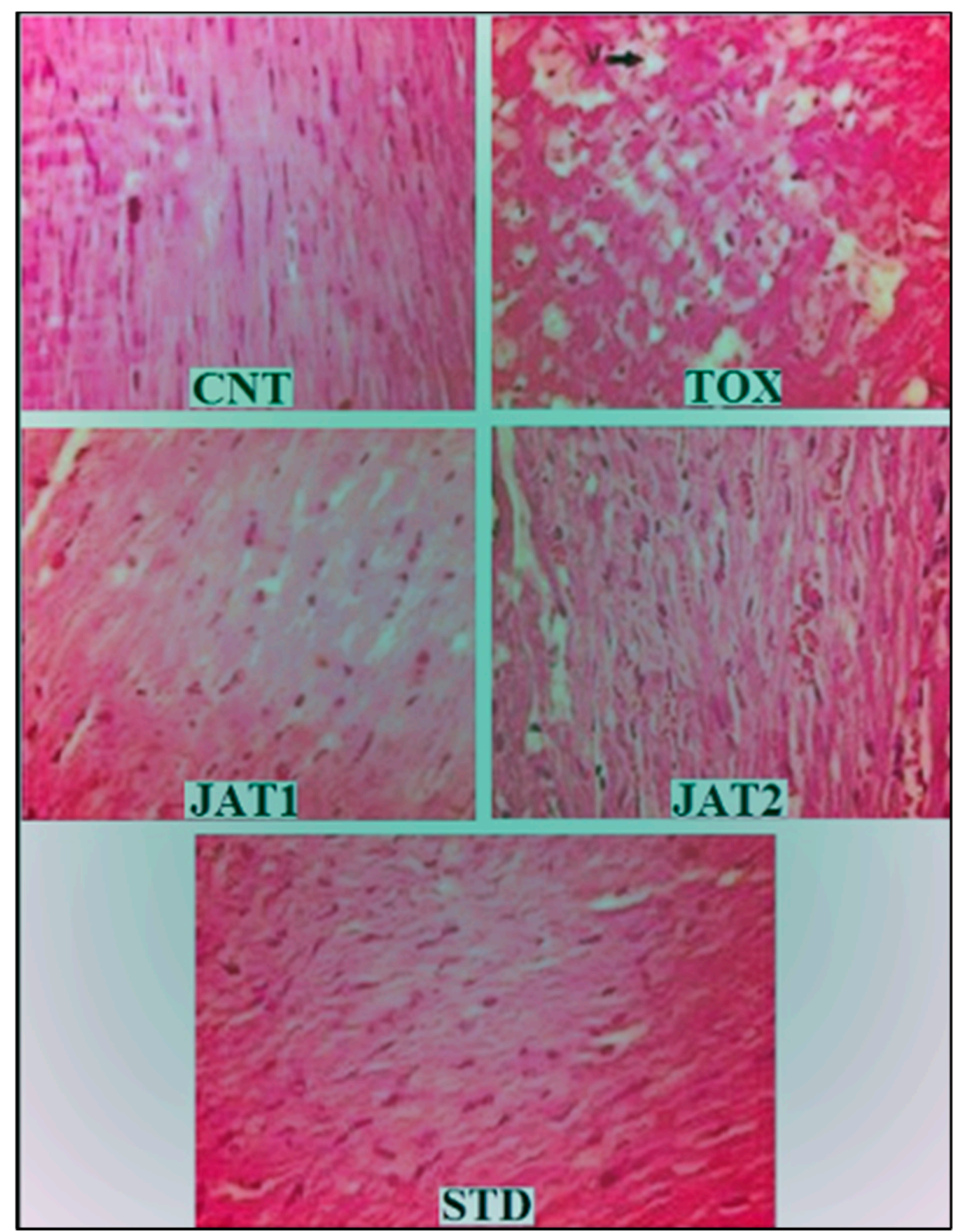

Figure 4. Histopathology of cardiac tissues from animals belonging to CNT, TOX group, MEJ groups, and STD-treated group was assessed with special reference to the integrity of myocardial fibre integrity and evidence of cardiac damage caused by DOX. CNT shows normal myocardial structure, whereas TOX shows disarray of myocardial cells with small and large vacuolar myopathy but no evidence of necrosis of the myocardium seen. Cardiac tissue from MEJ (JAT1, JAT 2) and STD groups, respectively, shows normal myocardial architecture. 


\section{Dicussion}

In the present study, MEJ was prepared and standardized using HPTLC fingerprinting, GC-MS profiling and total phenolic content estimation. In vitro antioxidant efficacy of extract was evaluated by DPPH assay and free radical scavenging test using nitric oxide. This standardized extract was further used for in vivo study to evaluate the possible effect of jatamansi in murine model of DOX cardiotoxicity by using oxidative stress, and inflammatory and apoptotic markers. Biochemical and histopathological changes observed upon administration of $15 \mathrm{mg} / \mathrm{kg}$ of DOX in divided doses over 3 weeks provided confirmatory evidence of its cardiotoxic potential.

DOX treatment for induction of cardiotoxicity also elevated CK-MB level by more than threefold. Increased CK-MB activity indicates myocardial infarction and rhabdomylosis. The present experiment showed that there was a significant increase in LDH level of DOX intoxicated rats. An increase in LDH level indicates cardiovascular damage induced by DOX and its metabolites. Lipid peroxidation was measured as nmol of MDA mg ${ }^{-1}$ of protein. Significant elevation in the MDA level was observed in the TOX group. Higher MDA levels can be due to DOX-induced oxidative damage.

Interleukin-6 plays a dual role both as a pro-inflammatory as well as anti-inflammatory cytokine. DOX is reported to cause IL- 6 release in addition to TNF- $\alpha$ and many mediators of apoptosis. These factors are believed to be responsible for its toxicity in the cardiac tissue [39]. We are reporting elevation of interleukin-6 level upon treatment with DOX as compared to the CNT group $(p<0.001)$. Wang et al. reported increased expression of interleukin 6 in the kidney tissue of DOX-treated rats [40]. These evidences suggest that the pro-inflammatory effect of DOX involves IL-6. Van der Veen et al. 2000 have reported the role of TNF-alpha in augmenting intra-tumoral concentration of DOX but the results do not define the role of TNF-alpha in modulating the DOX activity in vivo [41]. Chiosi et al. have reported that TNF-alpha activity is modulated by DOX in cardiomyocited to induced apoptosis, indicating the role of TNF-alpha signaling in DOX cardiotoxicity [42]. Results of our study revealed that DOX showed significant elevation in TNF-alpha level $(p<0.001)$ compared to the CNT group. TNF-alpha concentration increases in case of heart failure and is an independent predictor of mortality [43]. This showed that increased TNF-alpha level in the DOX-treated group could be due to induction of heart failure by DOX.

Results of estimation of apoptosis-specific enzyme caspase-3 activity in our study showed significant increase after DOX treatment. Previously, Sharma et al., confirmed that DOX-induced cardiotoxicity is mediated via caspase-3-dependent apoptotic pathway.

Treatment with test drug i.e., MEJ at the dose level of 250 and $500 \mathrm{mg} \mathrm{kg}^{-1}$ day $^{-1}$ orally up to 21 days significantly reduced elevated CK-MB levels $(p<0.001)$ in DOX-intoxicated rats. Treatment with MEJ $250 \mathrm{mg} \mathrm{kg}^{-1}$ significantly reduced elevated levels of MDA compared to TOX group, whereas treatment with MEJ $500 \mathrm{mg} \mathrm{kg}^{-1}$ also significantly reduced elevated levels of MDA compared to the TOX group. This indicated reduced lipid peroxidation in MEJ-treated groups. IL-6 is an interleukin, which has complex action on inflammatory pathways and is secreted by $\mathrm{T}$ cells and macrophages in response to inflammatory conditions. Elevated IL-6 levels are observed in DOX treatment in our study. This confirmed the previous studies, which reported that DOX cardiotoxicity is also mediated by inflammatory cytokines. Treatment with MEJ 250 and $500 \mathrm{mg} \mathrm{kg}^{-1}$ for 3 weeks caused reduction in IL-6 levels. TNF-alpha is a mediator of acute phase systemic inflammation and is reported to play a role in DOX-induced inflammation. Similar to IL-6, TNF-alpha level in MEJ group at 250 and $500 \mathrm{mg} / \mathrm{kg}$ showed significant reduction compared to TOX group. Elevated TNF-alpha levels were observed even after treatment with MEJ extract at 250 and $500 \mathrm{mg} \mathrm{kg}^{-1}$.

Caspase-3 activity, measured as a pro-apoptotic marker, after treatment with MEJ at a dose of $250 \mathrm{mg} \mathrm{kg}^{-1}$, showed significant difference compared to the TOX group. This indicated that caspase-3-mediated pro-apoptotic pathways were inhibited by MEJ at $250 \mathrm{mg} \mathrm{kg}^{-1}$ in DOX-treated rats.

Previously, HMG-CoA reductase inhibitor has been reported to protect against DOX-induced cardiotoxicity. Lovastatin, one of the HMG-CoA inhibitors, has been reported to have a synergistic effect with DOX in ovarian cancer cells. HMGCoA has also been implicated in the generation 
of ketone bodies. HMG-CoA is converted to acetoacetate, and acetyl-CoA by HMG-CoA lyase. The acetoacetate so formed is $\beta$-hydroxybutyrate, which is the ketone body present in highest amount in the body. While under normal physiological conditions, such ketone bodies perform multiple roles including energy provision. Excess ketone bodies formation is associated with free radical generation, oxidative stress and may lead to lipid peroxidation [44]. Since DOX is also reported to upregulate cholesterol transporter level in cardiac cholesterol transporter level [45], the association between DOX-induced oxidative stress and elevated HMGCoA levels warrant further study. Our study is the first to report the effect of DOX on serum HMG-CoA level in rats. Animals treated with MEJ were observed to have significantly lower serum HMG-CoA level than TOX group.

Further, studies are needed to investigate the mechanism and role of HMG-CoA in mediating various effects of DOX. Results of histopathology showed a protective effect of MEJ on disarrayed myocardial fibre in DOX-treated animals. This also depicted a primarily antioxidant property of the tested extract.

Nardostachys jatamansi contains jatamansone, jatamansic acid, lignans, and many other sesquiterpens. GC-MS analysis of MEJ showed that 32.05\% jatamansone is present in the prepared extract compare to other major constituents. High jatamansone content could be implicated for the antioxidant effect of MEJ, however, studies on isolated jatamanson are needed for DOX-induced myocardial injury. Inhibition of lipid peroxidation has also been used as a measure of activity of a herbal agent like Jatamansi for a very long time [46]. Subhashini et al. reported the cardioprotective effect of jatamansi, however, the study was majorly limited to an effect on mitochondrial damage due to DOX. Subhashini et al. has also proposed an antioxidant role of jatamansi in preventing DOX mitochondrial damage. The present study provides evidence on the antioxidant and cardioprotective role of jatamansi in DOX-induced oxidative stress [22]. Results of the present study also showed that MEJ did reduce proapoptotic and inflammatory markers. So, it can be concluded from the present study that MEJ can protect cardiac tissue from oxidative stress-induced cell injury and lipid peroxidation. It also interfered with DOX-induced inflammatory and apoptotic cascades in cardiac tissue. Therefore, the present experiment justifies the further development of jatamansi as a protective agent against DOX-induced cardiotoxicity.

Supplementary Materials: The following are available online at http://www.mdpi.com/2223-7747/9/11/1579/s1, Figure S1: HPTLC chromatogram (A) and developed HPTLC plate (B) of MEJ showing corresponding spot and peaks at $254 \mathrm{~nm}$.

Author Contributions: Conceptualization, M.S.; methodology, M.S. and K.Y.T.; software, M.A.K. and J.A.; formal analysis, M.A.K., J.A., U.A.F., S.K. and N.A.A.; investigation, M.S. and K.Y.T.; resources, J.A., U.A.F., S.K. and N.A.A.; data curation, M.A.K., K.Y.T., U.A.F., S.K. and N.A.A.; writing-original draft preparation, M.S.; writing-review and editing, S.A.; supervision, S.A.; project administration, S.A.; funding acquisition, S.A. All authors have read and agreed to the published version of the manuscript.

Funding: The Deanship of Scientific Research (DSR) at King Abdulaziz University, Jeddah, Saudi Arabia funded this project, under grant no (FP-167-42).

Acknowledgments: The Deanship of Scientific Research (DSR) at King Abdulaziz University, Jeddah, Saudi Arabia funded this project, under grant no (FP-167-42). The authors are thankful to Jamia Hamdard for providing facilities to carry out the research work.

Conflicts of Interest: The authors have declared that there are no conflicts of interest. 


\section{Abbreviations}

$\begin{array}{ll}\text { ANOVA } & \begin{array}{l}\text { Analysis of Variance } \\ \text { CK-MB }\end{array} \\ \text { CPCSEA } & \begin{array}{l}\text { Committee for the purpose of control and supervision } \\ \text { of experiment on animals } \\ \text { Doxorubicin }\end{array} \\ \text { DOX } & \text { 2,2-diphenyl-1-picrylhydrazyl. } \\ \text { DPPH } & \text { Enzyme Linke Immunosorbent Assay } \\ \text { ELISA } & \text { Gas chromatography-mass spectrometry } \\ \text { GC-MS } & \text { 3-hydroxy-3-methyl-glutaryl-coenzyme A } \\ \text { HMG-CoA } & \text { High-performance thin-layer chromatography } \\ \text { HPTLC } & \text { Interleukin-6 } \\ \text { IL-6 } & \text { Malondialdehyde } \\ \text { MDA } & \text { Nitric Oxide } \\ \text { NO } & \text { Thiobarbituric Acid } \\ \text { TBA } & \text { Tumor Necrosis Factor-Alpha } \\ \text { TNF- } \alpha & \end{array}$

\section{Appendix A}

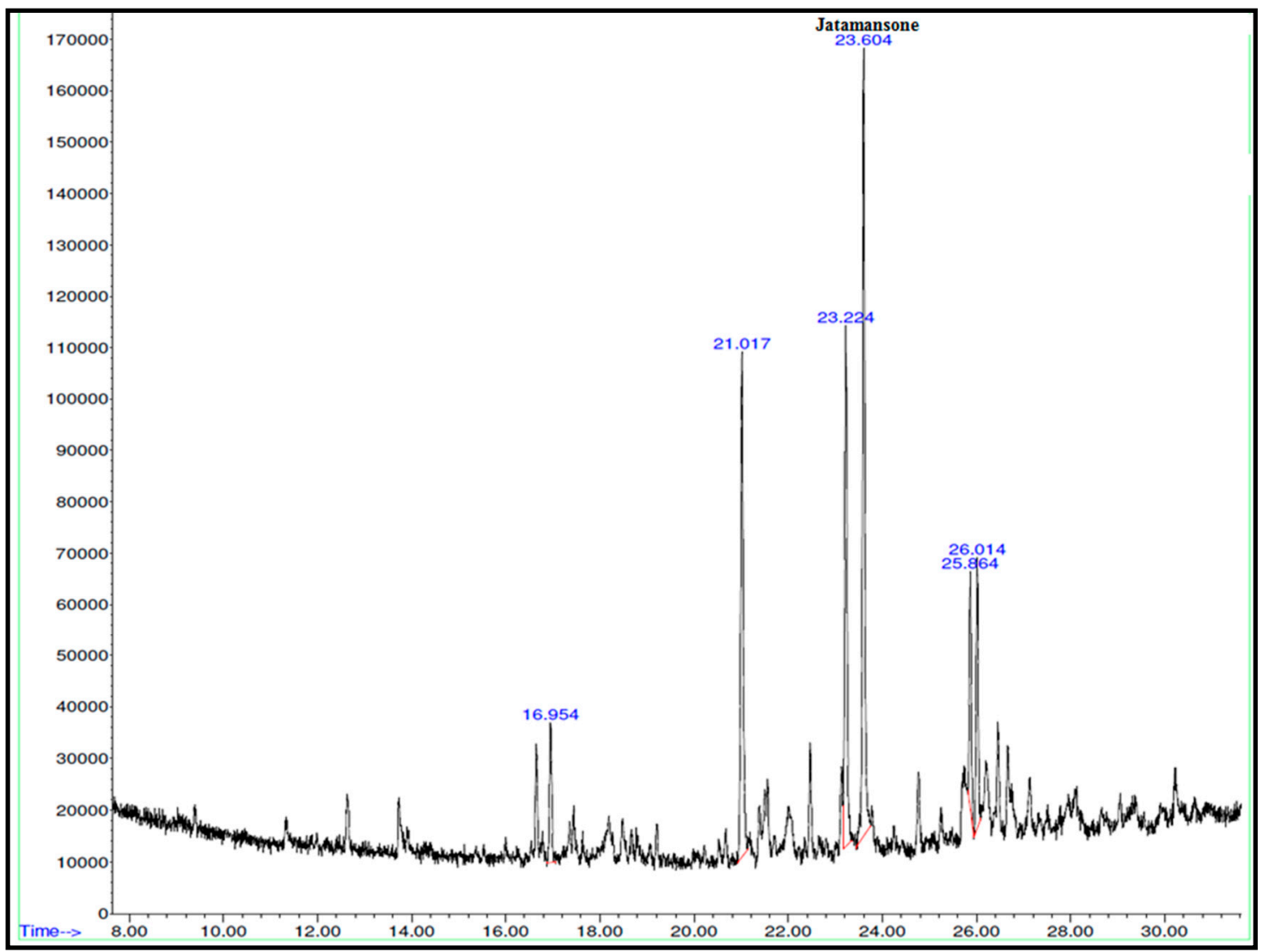

Figure A1. GC-MS chromatogram of hexane fraction of MEJ showing jatamansone as main constituent. 


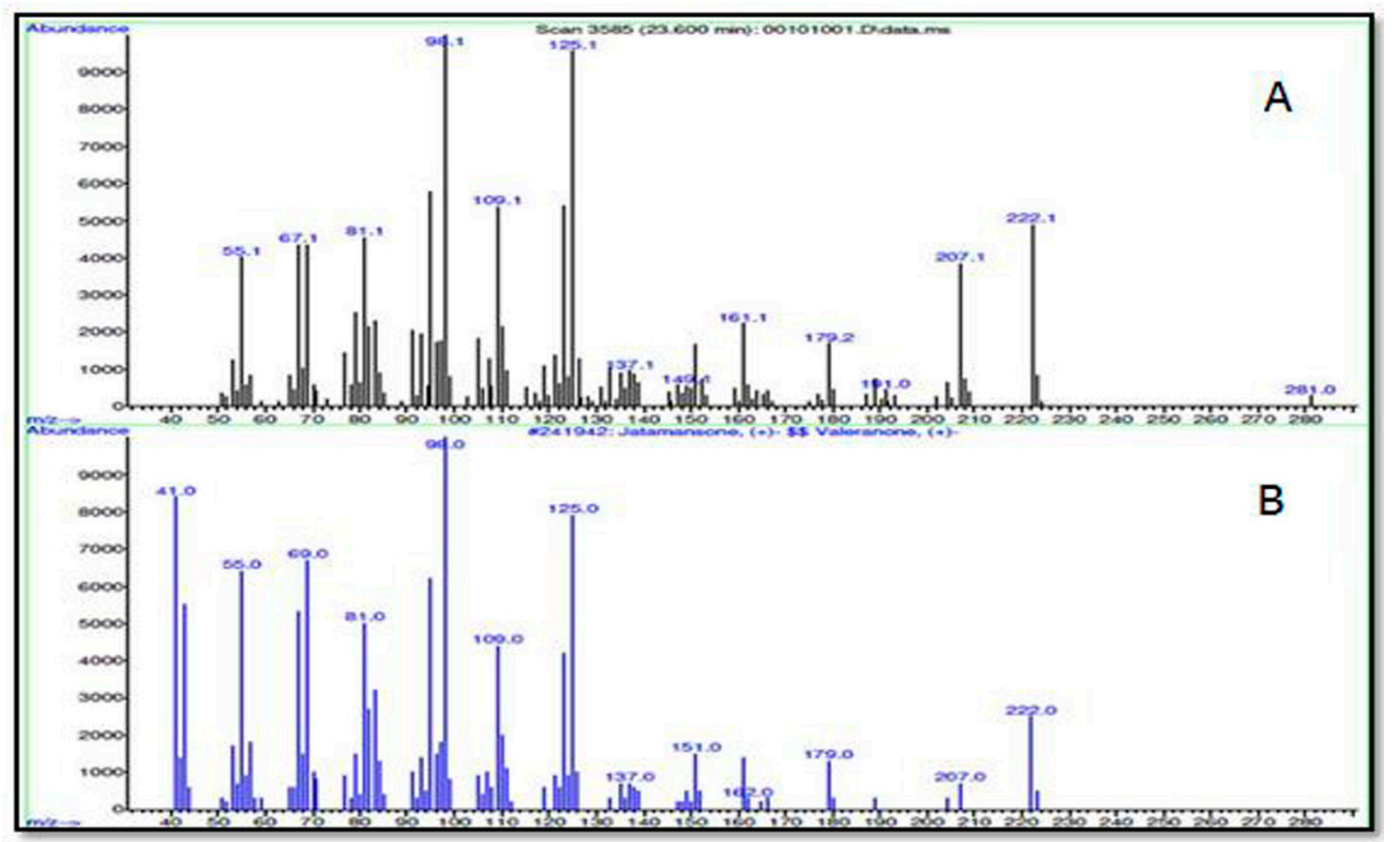

Figure A2. Mass spectra of jatamansone in sample (A) comparing with library (B) by GC-MS.

\section{References}

1. Keizer, H.G.; Pinedo, H.M.; Schuurhuis, G.J.; Joenje, H. DOX (adriamycin): A critical review of free radical-dependent mechanisms of cytotoxicity. Pharmacol. Ther. 1990, 47, 219-231. [CrossRef]

2. Zucchi, R.; Danesi, R. Cardiac toxicity of antineoplastic anthracyclines. Curr. Med. Chem. Anticancer Agents 2003, 3, 151-171. [CrossRef] [PubMed]

3. Lee, K.; Sung, R.Y.; Huang, W.Z.; Yang, M.; Pong, N.H.; Lee, S.M.; Chan, W.Y.; Zhao, H.; To, M.Y.; Fok, T.F.; et al. Thrombopoietin protects against in vitro and in vivo cardiotoxicity induced by DOX. Circulation 2006, 113, 2211-2220.

4. Neilan, T.G.; Blake, S.L.; Ichinose, F.; Raher, M.J.; Buys, E.S.; Jassal, D.S.; Furutani, E.; Perez-Sanz, T.M.; Graveline, A.; Janssens, S.P.; et al. Disruption of nitric oxide synthase 3 protects against the cardiac injury, dysfunction, and mortality induced by DOX. Circulation 2007, 116, 506-514. [CrossRef] [PubMed]

5. Arola, O.J.; Saraste, A.; Pulkki, K.; Kallajoki, M.; Parvinen, M.; Voipio-Pulkki, L.M. Acute DOX cardiotoxicity involves cardiomyocyte apoptosis. Cancer Res. 2000, 60, 1789-1792. [PubMed]

6. Fisher, P.W.; Salloum, F.; Das, A.; Hyder, H.; Kukreja, R.C. Phosphodiesterase-5 inhibition with sildenafil attenuates cardiomyocyte apoptosis and left ventricular dysfunction in a chronic model of DOX cardiotoxicity. Circulation 2005, 111, 1601-1610. [CrossRef] [PubMed]

7. Kawamura, T.; Hasegawa, K.; Morimoto, T.; Iwai-Kanai, E.; Miyamoto, S.; Kawase, Y.; Ono, K.; Wada, H.; Akao, M.; Kita, T. Expression of p300 protects cardiac myocytes from apoptosis in vivo. Biochem. Biophys. Res. Commun. 2004, 315, 733-738. [CrossRef]

8. Wang, G.W.; Klein, J.B.; Kang, Y.J. Metallothionein inhibits DOX-induced mitochondrial cytochrome release and caspase-3 activation in cardiomyocytes. J. Pharmacol. Exp. Ther. 2001, 298, 461-468.

9. Xu, X.; Persson, H.L.; Richardson, D.R. Molecular pharmacology of the interaction of anthracyclines with iron. Mol. Pharmacol. 2005, 68, 261-271. [CrossRef]

10. Calderone, A.; De Champlain, J.; Rouleau, J.L. Adriamycin-induced changes to the myocardial beta-adrenergic system in the rabbit. J. Mol. Cell Cardiol. 1991, 23, 333-342. [CrossRef]

11. Singal, P.K.; Iliskovic, N. DOX-induced cardiomyopathy. N. Engl. J. Med. 1998, 339, 900-905. [CrossRef] [PubMed]

12. Takemura, G.; Fujiwara, H. DOX-induced cardiomyopathy from the cardiotoxic mechanisms to management. Prog. Cardiovasc. Dis. 2007, 49, 330-352. [CrossRef] [PubMed] 
13. Minotti, G.; Menna, P.; Salvatorelli, E.; Cairo, G.; Gianni, 1. Anthracyclines: Molecular advances and pharmacologic developments in antitumor activity and cardiotoxicity. Pharmacol. Rev. 2004, 56, 185-229. [CrossRef] [PubMed]

14. Subashini, R.; Yogeeta, S.; Gnanapragasam, A.; Devaki, T. Protective effect of Nardostachys jatamansi on oxidative injury and cellular abnormalities during doxorubicin-induced cardiac damage in rats. J. Pharm. Pharmacol. 2006, 58, 257-262. [CrossRef] [PubMed]

15. Dixit, V.P.; Jain, P.; Joshi, S.C. Hypolipidaemic effects of Curcuma longa L and Nardostachys jatamansi, DC in triton-induced hyperlipidaemic rats. Indian J. Physiol. Pharmacol. 1988, 32, 299-304.

16. Joshi, H.; Parle, M. Nardostachys jatamansi improves learning and memory in mice. J. Med. Food 2006, 9, 113-118. [CrossRef]

17. Rao, V.S.; Rao, A.; Karanth, K.S. Anticonvulsant and neurotoxicity profile of Nardostachys jatamansi in rats. J. Ethnopharmacol. 2005, 102, 351-356. [CrossRef]

18. Bhat, M.D.A.; Malik, S.A. Efficacy of Nardostachys jatamansi (D.Don) DC in essential hypertension: A randomized controlled study. Complement. Ther. Med. 2020, 53, 102532. [CrossRef]

19. Bagchi, A.; Oshima, Y.; Hikino, H. Neolignans and lignans of Nardostachys jatamansi roots. Planta Med. 1991, 57, 96-97. [CrossRef]

20. Lyle, N.; Bhattacharyya, D.; Sur, T.K.; Munshi, S.; Paul, S.; Chatterjee, S.; Gomes, A. Stress modulating antioxidant effect of Nardostachys jatamansi. Indian J. Biochem. Biophys. 2009, 46, 93-98.

21. Bae, G.S.; Seo, S.W.; Kim, M.S.; Park, K.C.; Koo, B.S.; Jung, W.S.; Cho, G.H.; Oh, H.C.; Yun, S.W.; Kim, J.J.; et al. The roots of Nardostachys jatamansi inhibits lipopolysaccharide-induced endotoxin shock. J. Nat. Med. 2011, 65, 63-72. [CrossRef] [PubMed]

22. Subashini, R.; Gnanapragasam, A.; Senthilkumar, S.; Yogeeta, S.K.; Devaki, T. Protective efficacy of Nardostachys jatamansi (rhizomes) on mitochondrial respiration and lysosomal hydrolases during doxorubicin induced myocardial injury in rats. J. Health Sci. 2007, 53, 67-76. [CrossRef]

23. Subashini, R.; Ragavendran, B.; Gnanapragasam, A.; Yogeeta, S.K.; Devaki, T. Biochemical study on the protective potential of Nardostachys jatamansi extract on lipid profile and lipid metabolizing enzymes in doxorubicin intoxicated rats. Pharmazie 2007, 62, 382-387. [PubMed]

24. Slikard, K.; Singleton, V.L. Total phenol analysis: Automation and comparison with manual methods. Am. J. Enol. Vitic. 1977, 28, 49-55.

25. Kumaran, A.; Karunakaran, R.J. In vitro antioxidant activities of methanol extracts of five Phyllanthus species from India. LWT Food Sci. Technol. 2007, 40, 344-352. [CrossRef]

26. Liu, W.; Fu, Y.J.; Zu, Y.G.; Tong, M.H.; Wu, N.; Liu, X.L.; Zhang, S. Supercritical carbon dioxide extraction of seed oil from Opuntia dillenii Haw and its antioxidant activity. Food Chem. 2009, 114, 334-339. [CrossRef]

27. Ahmad, M.; Yousuf, S.; Khan, M.B.; Hoda, M.N.; Ahmad, A.S.; Ansari, M.A.; Ishrat, T.; Agrawal, A.K.; Islam, F. Attenuation by Nardostachys jatamansi of 6-hydroxydopamine-induced parkinsonism in rats: Behavioral, neurochemical, and immunohistochemical studies. Pharmacol. Biochem. Behav. 2006, 83, 150-160. [CrossRef]

28. Lyle, N.; Gomes, A.; Sura, T.; Munshi, S.; Paul, S.; Chatterjee, S.; Bhattacharyya, D. The role of antioxidant properties of Nardostachys jatamansi in alleviation of the symptoms of the chronic fatigue syndrome. Behav. Brain Res. 2009, 202, 285-290. [CrossRef]

29. Momin, F.N.; Kalai, B.R.; Shikalgar, T.S.; Naikwade, N.S. Cardioprotective effect of methanolic extract of Ixora coccinea Linn. leaves on doxorubicin-induced cardiac toxicity in rats. Indian J. Pharmacol. 2012, 44, 178-183. [CrossRef]

30. Thippeswamy, A.H.; Shirodkar, A.; Koti, B.C.; Sadiq, A.J.; Praveen, D.M.; Swamy, A.H.; Patil, M. Protective role of Phyllantus niruri extract in doxorubicin-induced myocardial toxicity in rats. Indian J. Pharmacol. 2011, $43,31-35$.

31. Lum, G.; Gambino, S.R. A comparison of serum versus heparinized plasma for routine chemistry tests. Am. J. Clin. Pathol. 1974, 61, 108-113. [CrossRef] [PubMed]

32. Lehmann, G.L.; Carreras, F.I.; Soria, L.R.; Gradilone, S.A.; Marinelli, R.A. LPS induces the TNF-alpha-mediated down regulation of rat liver aquaporin-8: Role in sepsis-associated cholestasis. Am. J. Physiol. Gastrointest. Liver Physiol. 2008, 294, 567-575. [CrossRef] [PubMed]

33. Helle, M.; Boeije, L.; Groot, E.D.; Vos, A.D.; Aarden, L. Sensitive ELISA for interleukin-6: Detection of IL-6 in biological fluids: Synovial fluids and sera. J. Immunol. Methods 1991, 138, 47-56. [CrossRef] 
34. Jaeschke, H.; Fisher, M.A.; Lawson, J.A.; Simmons, C.A.; Farhood, A.; Jones, D.A. Activation of caspase 3 (CPP32)-like proteases is essential for TNF- $\alpha$-induced hepatic parenchymal cell apoptosis and neutrophil-mediated necrosis in a murine endotoxin shock model. J. Immunol. 1998, 160, 3480-3486.

35. Iqbal, M.; Dubey, K.; Anwer, T.; Ashish, A.; Pillai, K.K. Protective effects of telmisartan against acute doxorubicin-induced cardiotoxicity in rats. Pharmacol. Rep. 2008, 60, 382-390.

36. Lowry, O.H.; Rosebrough, N.J.; Farr, A.L.; Randall, R.J. Protein measurement with the folin phenol reagent. J. Biol. Chem. 1951, 193, 265-275.

37. Sharma, H.; Pathan, R.A.; Kumar, V.; Javed, S.; Bhandari, U. Anti-apoptotic potential of rosuvastatin pretreatment in murine model of cardiomyopathy. Int. J. Cardiol. 2011, 150, 193-200. [CrossRef]

38. Tanaka, M.; Kuei, C.W.; Nagashima, Y.; Taguchi, T. Application of antioxidative maillrad reaction products from histidine and glucose to sardine products. Nippon Suisan Gakk 1998, 54, 1409-1414. [CrossRef]

39. Nebigil, C.G.; Désaubry, L. Updates in anthracycline-mediated cardiotoxicity. Front. Pharmacol. 2018, 9, 1262. [CrossRef]

40. Wang, L.M.; Chi, Y.J.; Wang, L.N.; Nie, L.; Zou, Y.H.; Zhao, T.N.; Li, C.Y.; Chen, M.; Huo, M.X. Expression of interleukin-6 in rat model of doxorubicin-induced nephropathy. Zhongguo Dang Dai Er Ke Za Zhi 2010, 12, 912-914.

41. Van der Veen, A.H.; De Wilt, J.H.; Eggermont, A.M.; Van Tiel, S.T.; Seynhaeve, A.L.; Ten Hagen, T.L. TNF-alpha augments intratumoural concentrations of doxorubicin in TNF-alpha-based isolated limb perfusion in rat sarcoma models and enhances anti-tumour effects. Br. J. Cancer 2000, 82, 973-980. [CrossRef] [PubMed]

42. Chiosi, E.; Spina, A.; Sorrentino, A.; Romano, M.; Sorvillo, L.; Senatore, G.; D'Auria, R.; Abbruzzese, A.; Caraglia, M.; Naviglio, S.; et al. Change in TNF-alpha receptor expression is a relevant event in doxorubicin-induced H9c2 cardiomyocyte cell death. J. Interferon Cytokine Res. 2007, 27, 589-597. [CrossRef] [PubMed]

43. Schulz, R.; Aker, S.; Belosjorow, S.; Heusch, G. TNF-alpha in ischemia/reperfusion injury and heart failure. Basic Res. Cardiol. 2004, 99, 8-11. [PubMed]

44. Grabacka, M.; Pierzchalska, M.; Dean, M.; Reiss, K. Regulation of ketone body metabolism and the role of PPAR $\alpha$. Int. J. Mol. Sci. 2016, 17, 2093. [CrossRef]

45. Monzel, J.V.; Budde, T.; Meyer, Z.; Schwabedissen, H.E.; Schwebe, M.; Bien-Möller, S.; Lütjohann, D.; Kroemer, H.K.; Jedlitschky, G.; Grube, M. Doxorubicin enhances oxysterol levels resulting in a LXR-mediated upregulation of cardiac cholesterol transporters. Biochem. Pharmacol. 2017, 144, 108-119. [CrossRef]

46. Tripathi, Y.B.; Tripathi, E.; Upadhyay, A. Antilipid peroxidative property of Nardostachys jatamanasi. Indian J. Exp. Biol. 1996, 34, 1150-1151.

Publisher's Note: MDPI stays neutral with regard to jurisdictional claims in published maps and institutional affiliations.

(C) 2020 by the authors. Licensee MDPI, Basel, Switzerland. This article is an open access article distributed under the terms and conditions of the Creative Commons Attribution (CC BY) license (http://creativecommons.org/licenses/by/4.0/). 